\title{
The Concepts of Partnerships and Accountability
}

Before launching into normative reflections on accountability in Chapter 3, this chapter develops a basic understanding of the central terms around which this book is structured and sketches the necessary background and context for locating the debate.

\subsection{Partnerships}

Nowadays, partnerships are everywhere. Visit the website of any major international institution, government, large corporation and - increasingly non-governmental organisation (NGO) and you will most likely find some information about this organisation's partnership programmes or philosophy. Similarly, if you participate in a conference on governance issues or global public policy ${ }^{1}$ problems, the odds that 'partnerships' will be on the agenda are good. ${ }^{2}$

As mentioned in the Introduction, partnerships today address a wide range of issues. As a result, the term 'partnership' is nearly ubiquitous. It is used to describe many different and often contradictory phenomena. ${ }^{3}$ To be able to use the term in a social scientific context, this section defines its essential characteristics and distinguishes it from other concepts, namely networks and corporatism.

\subsubsection{Definition}

For the purposes of this book, 'partnership' is defined in an ideal typical way $^{4}$ as a voluntary cooperative arrangement

- between organisations from the public, private and/or civil society sectors. The public sector includes public institutions at the local, regional, national and inter- or supranational level. The private sector includes small- and medium sized, as well as large and trans- or multinational companies. Civil society organisations can range from local, communitybased organisations to large, transnational development initiatives. 
- that display a certain degree of institutionalisation. While partnerships are often dynamic in their composition and working methods and don't need to follow a uniform or standardised institutional model, they must show a minimum of formality. This minimum includes a clear understanding of who the partners are, some regular form of consultation and agreed decision-making procedures.

- that have common, non-hierarchical decision-making procedures and share risks and responsibilities. Different organisations cooperating on an equal footing and determining policies and action plans jointly is what transforms any working relationship into a partnership. Of course, that does not mean that partnerships know no power differentials between their partner organisations or that decision-making procedures cannot in any way reflect these differences. But for a cooperative relationship to be a partnership, all partner institutions have to be involved in a significant way in the taking of important decisions. This also implies that partner organisations share risks and responsibilities involved in the partnership.

- whose purpose is to address a public policy issue. Partnerships are of interest in the context of political science insofar as they work to achieve a societal goal and thus complement or substitute the work of governmental actors. This criterion, however, is not a very strict one, since many governments have been liberal in defining what constitutes a public policy issue.

In brief, 'partnership' is defined as a voluntary cooperative arrangement, involving public, private and/or civil society organisations that is formalised with common, non-hierarchical decision-making procedures and that addresses a public policy issue.

At the global level, partnerships address a broad range of issues. The Partnership for Clean Fuels and Vehicles (PCFV), for example, aims at reducing air pollution caused by vehicles in developing countries. The Internet Corporation for Assigned Names and Numbers (ICANN) regulates the technical elements of the Internet's name and numbering systems in order to preserve the operational stability of the system and promote competition. The Extractive Industries Transparency Initiative (EITI) aims to increase transparency and accountability to ensure that the revenues derived from extractive industries contribute to sustainable development and poverty reduction. The Global Alliance for Improved Nutrition (GAIN) seeks to reduce malnutrition of populations at risk through the fortification of staple foods and other strategies, and the Common Code for the Coffee Community (4C) promotes sustainability in the production, processing and trading of mainstream coffee by compiling and promoting relevant standards.

The definition employed here shares some common traits but also displays significant differences with some other definitions of partnerships employed in a social scientific or practical-political context. 
The Political Declaration of the WSSD in Johannesburg, which was so instrumental in promoting the concept of partnership by including it as an official, 'type $\mathrm{II}^{\prime}$, outcome of the summit, contains no more than the following:

We recognize that sustainable development requires a long-term perspective and broad-based participation in policy formulation, decision-making and implementation at all levels. As social partners, we will continue to work for stable partnerships with all major groups, respecting the independent, important roles of each of them.

(World Summit on Sustainable Development, 2002a, § 26)

The Johannesburg Plan of Implementation that was adopted along with the political declaration is slightly more detailed in that it specifies the involvement of 'major groups' in partnerships. At the same time, it constricts the definition to include only cooperative arrangements focusing on policy implementation (rather than policy definition, for example) in the area of sustainable development.

[T] he implementation should involve all relevant actors through partnerships, especially between Governments of the North and South, on the one hand, and between Governments and major groups, on the other, to achieve the widely shared goals of sustainable development. As reflected in the Monterrey Consensus, such partnerships are key to pursuing sustainable development in a globalizing world.

(World Summit on Sustainable Development, 2002b, § 3)

This definition of partnerships and the subsequent work of the UN are, however, based on a more detailed description of criteria for partnerships. The criteria were developed in the run-up to WSSD and endorsed in the decision of the eleventh meeting of the Commission on Sustainable Development. Like the definition proposed here, they recognise partnerships as voluntary, multi-stakeholder initiatives. But they only focus on initiatives designed to contribute to the implementation of internationally agreed development goals and include a range of normative criteria, such as that partnerships should pursue an integrated approach to sustainable development, display a sectoral and geographical balance and be designed in a transparent and accountable manner. ${ }^{5}$

The WSSD's focus on cooperation in order to achieve a public policy goal is echoed in the political science literature, for example, in Börzel and Risse, who focus on partnerships that transcend national borders:

Transnational PPPs [public-private partnerships] would then be institutionalized cooperative relationships between public actors (both governments 
and international organizations) and private actors beyond the nationstate for governance purposes, [i.e. for] the making and implementation of norms and rules for the provision of goods and services that are considered as binding by members of the international community.

(Börzel and Risse, 2005, p. 199)

By contrast, the Food and Drug Administration (FDA), a US government agency that actively encourages 'partnering with the private sector', sees partnerships as a predominantly commercial relationship and therefore includes only financial restrictions in its definition:

For example, a public/private partnership could be an arrangement whereby a contractor or third party develops and operates a system which is beneficial to the FDA and others and charges the cost of the service to users. Revenue generated by the system would be expended by the contractor or third party to maintain and improve the system.

(United States Food and Drug Administration, 2004, p. 1)

In a similar vein, the German government's definition of partnerships focuses on co-financing mechanisms - mainly in the context of development policies.

We take 'public private partnerships' to be development partnerships with the private sector. Partnerships consist of projects that are co-financed by corporations and development agencies.

(Gesellschaft für Technische Zusammenarbeit, 2004)

(Author's translation) ${ }^{6}$

A comparable emphasis on the financial aspects of a partnership appears, for example, in Lindner and Rosenau - though they focus more on traditional contracting-out models, where the government plays the role of the financier that pays the private sector to provide public services, rather than the user-fee or co-financing models emphasised above by the governments:

[We generalise] the partnership notion to include almost any combination of public funding and private provision of services for public purposes.

(Linder and Rosenau, 2000, p. 7)

In some respects, then, the definition of 'partnerships' proposed here is narrower than other definitions in use (most notably with respect to the common decision-making criterion), while in others it is wider than at least some others (e.g. on the type of actors involved or the purposes pursued by the partnership). 
While these definitions differ from one another in various respects, they all belong to the same emerging discourse that places partnerships in the context of a public policy or governance context. As such, they have a significantly different understanding of the term than a standard dictionary definition such as Merriam-Webster's that defines 'partnership' as a legal term.

[A partnership is] a legal relation existing between two or more persons contractually associated as joint principals in a business, or a relationship resembling a legal partnership and usually involving close cooperation between parties having specified and joint rights and responsibilities.

(Merriam-Webster, 2004, entry for 'partnership')

\subsubsection{Partnerships between networks and corporatism}

While the term 'partnership' is by now much used in political practice and analysis, there is no extended theoretical work establishing a theory of policy partnerships. Networks and corporatism, by contrast, are concepts or models with a much longer and more refined theoretical pedigree. Both terms deal with modes of policymaking that include actors from the private and/or civil society sectors and have been applied to the study of partnerships. This section provides a brief summary of both traditions of thought and explains the overlaps and differences as compared to the partnership concept used here.

\subsubsection{Corporatism}

Corporatism is a political system that provides for a legal representation of different industrial, economic and professional groups and their inclusion in political decision-making processes. ${ }^{7}$ Early proponents of corporatist political structures such as Adam Müller saw corporatism as a way to transform class conflict into class cooperation. Fascist economic theory and practice drew heavily on this concept, contributing to the negative associations made with the term today. ${ }^{8}$

Are partnerships between governmental organisations, corporations and civil society organisations, then, just a revival of corporatist structures under a new guise? This, in fact, is one of the more powerful criticisms that have been directed against proposed and existing partnerships. ${ }^{9}$

Some significant parallels exist between corporatism and partnerships that warrant a careful analysis of the arguments made and evidence collected in the literature about corporatism. First, corporatism, like partnerships, is about including organised interests in the policymaking process. As a consequence, the participation of individuals in the political process takes a setback in both arrangements - an argument that is particularly important for partnerships operating at the national or local level. At the same time, this means that in both cases the participation of groups can be regulated, thereby potentially minimising existing inequalities of access to people in power. 
Second, some thinkers such as John Ralston Saul have described corporatism as a system in which organised elites get to influence the policy process at the expense of ordinary citizens. ${ }^{10}$ The same argument has been debated with respect to NGOs. ${ }^{11}$ For the question whether NGOs are an elite project, one should certainly differentiate between different types of civil society organisations, for example, between large and established institutions operating at an international level such as Amnesty International and small, community-based organisations. But when analysing partnerships between governmental organisations, corporations and civil society groups, one must bear in mind that large NGOs possess far greater visibility and resources for engaging in high-profile partnerships than grassroots organisations. ${ }^{12}$

Finally, both partnerships and corporatist solutions can have their most positive impact in policy areas rife with conflict. Addressing these conflicts through cooperative approaches does not only mitigate social unrest, it also improves compliance with the decisions taken. This aspect becomes the more important, the weaker the central control mechanisms of the political system in question are.

But there are also important differences between these two concepts. First, corporatist political systems normally only include labour and business interests and focus on macroeconomic policy decisions. Partnerships can include these, but are rarely restricted to them. Rather, partnerships can cover the entire spectrum of policy issues. In each case, they will gather those groups that can affect the outcome and contribute to solving the problem addressed. Thus, for example, the World Commission on Dams (WCD) was composed of representatives of governments interested in large dam projects, companies specialised in building these large projects and civil society groups representing those affected by the dams, who were previously often engaged in violent protests against the dam projects. ${ }^{13}$

Second, the groups included in corporatist governance structures tend to be highly centralised, with business as well as labour organisations representing entire sectors. Partnerships, by contrast, often include small community-based organisations representing one very specific section of society or individual businesses whose operations have an impact on the goals of the partnership.

Finally, corporatism is a system that usually operates in the context of a national political system. ${ }^{14}$ As such, its decision-making structures ultimately depend on the authority of the state. This can, but does not have to, lead to hierarchical decision-making procedures in corporatist institutions. Partnerships also work at the inter- or transnational level. While partnerships thus often operate 'in the shadow of hierarchy', ${ }^{15}$ their decision-making processes by definition have to be non-hierarchical. Therefore only those corporatist arrangements with common and non-hierarchical decisionmaking procedures would qualify as partnerships. 


\subsubsection{Networks}

Networks are the subject of an impressive body of literature in anthropology, sociology, political science and economics. Naturally, these studies contain a broad variety of approaches, themes and focal points. When trying to establish how networks relate to partnerships, it is useful to distinguish three modes of network research: network analysis, network theories or models and networks as empirical phenomena.

As an analytical approach, network analysis had an early precursor in the sociological work of Georg Simmel ${ }^{16}$ around the turn of the last century. It developed into a more widespread and coherent approach in sociology and anthropology ${ }^{17}$ in the 1970s and has further developed since. In essence, network analysis is an approach to social enquiry that focuses on the interactions between individuals or organisations. To understand certain dynamics or outcomes, it typically maps the links and exchanges between different actors, often using complex mathematical and statistical tools. Based on patterns of interaction or the position of different actors in the network, situations can be classified. ${ }^{18}$

In political science, policy network analysis is closely associated with the notion of 'governance'. ${ }^{19}$ Governance theories and approaches often take the diminished capability of central government to govern using traditional methods as their point of departure ${ }^{20}$ and focus on ways of steering by political authorities. ${ }^{21}$ Over recent years, a vast body of literature discussing the concept of governance and applying network approaches to policy analysis has developed. Yet the cumulative insights derived from the governance debate seem limited and network analysis as an analytical approach has serious shortcomings. ${ }^{22}$ Moreover, a network approach is ill suited for achieving the purposes of the present enquiry, namely, to develop accountability standards for partnerships. Therefore, this study does not adopt a network approach to social analysis.

Network theory, by contrast, is mainly concerned with explaining why networks emerge, how they operate and what impact they have on social interactions. An important source of network theory is transaction cost analysis. It posits that firms choose that organisational form which allows them to minimise their transaction costs in the production and marketing process. Thus they can either rely on the market, on hierarchies (i.e. the vertical integration of suppliers) or networks of known and trusted firms to secure needed inputs and sell their products. ${ }^{23}$ Unfortunately, 'network theory' does not constitute a coherent body of work ${ }^{24}$ generating a consistent set of assumptions and hypotheses. While some specific network theories may offer interesting insights relating to the emergence and operations of partnerships, they are unlikely to contribute much to the question of how accountable partnerships should be.

Finally, the term 'network' is used as an empirical category. Since the applications of network analysis and theories are extremely broad, so are the 
descriptions of what constitutes an actual network. Delimitating the fuzzy notion of 'partnership' from the equally ill-defined notion of 'network' can therefore seem a futile task. ${ }^{25}$ Yet when concentrating on policy networks, two broad approaches can be distinguished. Most authors employ a broad definition of networks, which encompasses all non-hierarchical forms of linkages among actors involved in the policy process. This can range from entirely informal and fluid arrangements with no fixed decision-making procedures to highly formalised corporatist structures or intergovernmental policy-coordination mechanisms. ${ }^{26}$ What these arrangements have in common is that the actors are mutually dependent on each other for solving the problem at hand and seek to coordinate their activities to that aim. ${ }^{27}$

As represented in Figure 2.1, if this wide definition of networks is used, partnerships can be understood as a specific form of network. A possible conceptual alternative to 'partnership' would therefore be 'institutionalised network'. But, apart from the heavy and often problematic theoretical baggage referred to above, the concept of 'network' also has a narrow definition with connotations that do not fit the subject of this investigation well. Take, for example, Grahame Thompson's definition of networks:

Networks have often been considered as above all 'informal' practices of coordination. They rely upon direct personal contact. They tend to be localized as a result, or confined to a particular clearly defined group with similar concerns, interests or aspirations. Such that they display a systematic orientation, these work through attributes like loyalty and

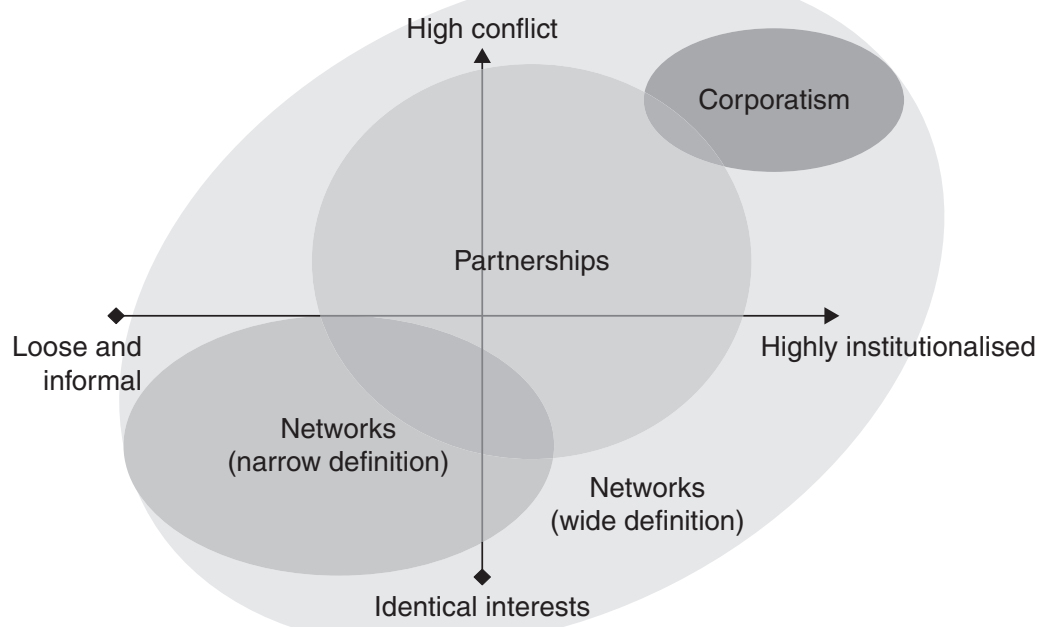

Figure 2.1 Partnerships, networks and corporatism 
trust rather than administrative orders or prices. [...] Governance of an activity is achieved through the identity of a common purpose or interest, for which all will work for a collective result. These tend towards a 'flat' organizational structure, where at least there is a lot of formal equality between the participants (though there may actually be significant real differences of power and authority in practice).

(Thompson, 2003, pp. 30-1)

This description suggests that networks arise among actors with similar interests and therefore only need a low degree of institutionalisation to coordinate their activities. Partnerships, by contrast, often form among actors with strongly diverging interests. To find cooperative solutions which benefit all participants, clearer rules and decision-making procedures as well as stronger commitments by the partner organisations are required. It is due to these connotations of extremely loose structures, identity of interest and the dominance of trust and loyalty ${ }^{28}$ that the term 'partnership' is preferred here over 'institutionalised networks'.

\subsection{Accountability}

As indicated in the opening pages of this book, the concept of accountability is highly complex. Yet accountability does have a specific core meaning. This section proposes a general, 'core' definition of accountability, clarifies the concept by asking the questions 'who is accountable, to whom, for what, how and why?' and explores some of the general problems and dilemmas of accountability.

\subsubsection{Defining the 'core' of accountability}

A standard dictionary definition of accountability reads as follows:

[Accountability is] the quality or state of being accountable; especially: an obligation or willingness to accept responsibility or to account for one's actions.

(Merriam-Webster, 2004, entry for 'accountability', emphasis original)

That definition contains two central elements: the notion of responsibility and that of accounting for something. The original meaning of 'to account', in turn, is the 'reckoning of money received and paid' (Douglas-Harper, entry for 'account'). Accounting, then, primarily refers to the keeping and transmitting of information. This meaning is reflected in our understanding of 'accountants', that is, professional bookkeepers. In this context 'accounting' is neutral, in the sense that it only implies an accurate reporting of facts, not an evaluation of these facts. 
When we say 'to account for', though, the term has a different connotation. According to an etymological dictionary, it was around 1700 that the term started to be used in the sense of 'explaining' and 'answering for money held in trust'. ${ }^{29}$ This is where the 'responsibility' part of the definition stems from. People entrust their money to others, who accept the responsibility to deal with it according to the terms agreed. 'Accounting for', then, means not only transmitting accurate information about the use of that money but also explaining whether the money was handled as agreed.

From the perspective of an actor (often termed the 'agent'), then, 'accountability' means:

- providing accurate information about one's activities or behaviour;

- evaluating that behaviour with reference to certain standards, rules or expectations;

- thereby recognising one's obligations and accepting responsibility for one's actions.

But accountability always involves a second side, since it is a concept that refers to the relationship between at least two actors. In the dictionary's example, the other side are the people who entrusted their money to somebody else (often termed the 'principal'). They are only prepared to delegate control over their property to an agent if they can trust that the agent will honour his obligations and act in their best interest. To be able to hold the agent accountable for doing so, the principals need sufficient information about the agent's behaviour. They also need to maintain some leverage over the agent, that is, the ability to impose positive or negative sanctions. In a working accountability relationship, the principal's ability to impose sanctions and the agent's anticipation of these sanctions are sufficient to control the agent's behaviour.

From the perspective of the principal, then, accountability is a mechanism to ensure that the agent does not abuse his authority and acts in the best interest of the principal. It is at this point that the concepts of accountability and legitimacy intersect. Where a principal has access to sufficient accountability mechanisms, he is likely to regard the agent's exercise of authority as legitimate. Because of this connection, many authors writing from a political background have a habit of mentioning both terms in the same breath and of using them almost interchangeably. ${ }^{30}$ Yet the concepts are different and it is important to be aware of their distinctions.

'Legitimacy' is a term used in political science to designate a situation in which citizens accept the authority of the government and are therefore prepared to comply with its policies. ${ }^{31}$ In his early treatment of the subject, Max Weber emphasised that legitimacy can have several sources, including tradition and charisma, as well as the formal correctness and legality of the act of ruling. ${ }^{32}$ In the context of today's democratic discourse, it is more 


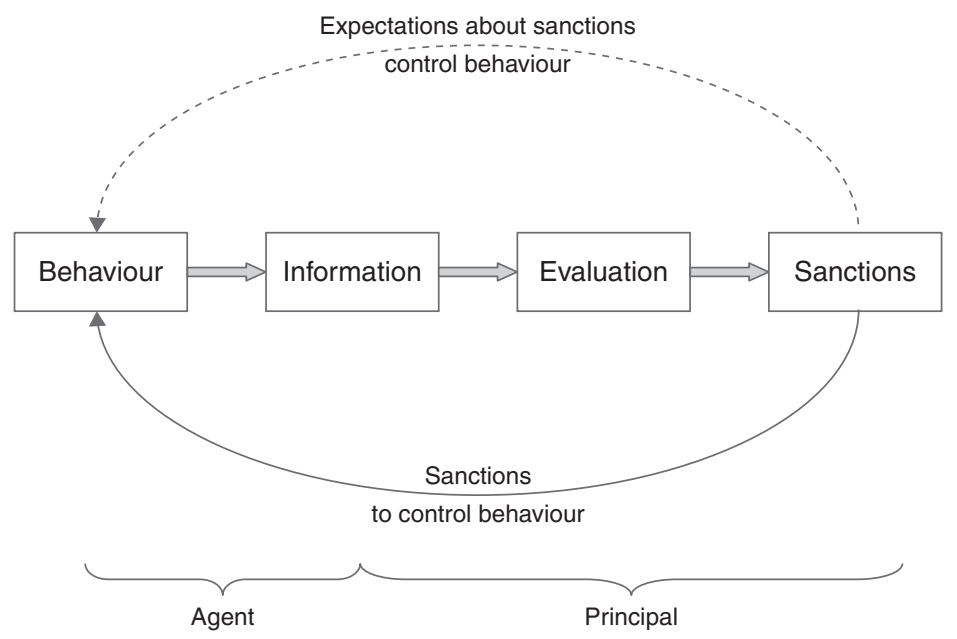

Figure 2.2 Accountability

commonplace to acknowledge that legitimacy can derive from the use of appropriate inputs or processes, as well as the achievement of desirable outputs or results. ${ }^{33}$ In a democratic understanding of governance, appropriate accountability arrangements create input accountability. ${ }^{34}$ But legitimacy can also derive from the effectiveness or efficiency of an organisation in achieving results, which does not require a similar accountability relationship.

The basic mechanism of accountability is represented in Figure 2.2. An agent behaves within the context of a certain set of obligations and expectations. ${ }^{35}$ Information about this behaviour can either be provided by the agent herself or demanded and generated by the principal. The principal then evaluates this information and applies positive or negative sanctions accordingly. Insofar as the agent can anticipate this reaction, she can adapt her behaviour to avoid negative sanctions.

In the previous paragraphs, I have used the terms 'principal' and 'agent' to designate the accountability holder and holdee respectively. The terms derive from principal-agent theory, an important theoretical construct in economics. The theory was originally designed to analyse the relationship between the owners and managers of companies. Over time, this reasoning has been applied to a wide array of situations, relaxing some of the stricter assumptions of the economic formulations of the theory.

In an early paper on the problems arising in principal-agent arrangements, Stephen Ross defined the basic relationship as follows:

[A]n agency relationship has arisen between two (or more) parties when one, designated as the agent, acts for, on behalf of, or as a representative 
for the other, designated the principal, in a particular domain of decision problems.

The theory assumes that both parties are autonomous actors and rational agents who want to maximise their expected utility. In most cases the principal's utility function differs from the agent's utility function, and that's where the problem starts. The agent does not automatically act in the best interest of the principal. Since the activity takes place in an environment containing unpredictable developments which cannot be influenced by the agent, not all aspects of the agent's behaviour can be predetermined in detail. In addition, the relationship involves an information asymmetry because the agent will always be better informed about his activities than the principal. ${ }^{36}$

Because of these three elements - diverging goals, a situation of uncertainty and information asymmetry - a principal-agent relationship brings disadvantages to the parties involved. These so-called agency costs arise either from the efforts needed to make the agent act in the best interest of the principal or from the loss incurred if the agent's activities diverge from the outcome preferred by the principal. ${ }^{37}$

To limit the negative impacts of principal-agent relationships - or, in other words, to improve the accountability of the agent to the principal economists have focused their attention on two aspects of the relationship: the definition of sanctions and incentives to align the interests of agent and principal and the provision of information to reduce the principal's monitoring costs. In a business context, solutions usually involve remuneration schemes for managers linking their income to company profits and strictly regulated and audited financial reporting mechanisms.

Economists working on principal-agent theory early on stressed the possibilities of expanding their reasoning to other social or political relations. Thus, Jensen and Meckling noted:

Before moving on, however, it is worthwhile to point out the generality of the agency problem. The problem of inducing an 'agent' to behave as if he were maximizing the 'principal's' welfare is quite general. It exists in all organizations and in all cooperative efforts - at every level of management in firms, in universities, in mutual companies, in cooperatives, in governmental authorities and bureaus, in unions, and in relationships normally classified as agency relationships such as those common in the performing arts and the market for real estate. The development of theories to explain the form which agency costs take in each of these situations (where the contractual relations differ significantly), and how and why they are born will lead to a rich theory of organizations which is now lacking in economics and the social sciences generally.

(Jensen and Meckling, 1976, p. 313) ) $^{38}$ 
Particularly political scientists focusing on democratic accountability have taken up this suggestion and have applied the insights derived from economic analysis to political processes. In many cases they have also adopted the focus on sanctions/incentives and the provision of information. Thus Andreas Schedler defines political accountability as follows:

[T] he notion of political accountability carries two basic connotations: answerability, the obligation of public officials to inform about and to explain what they are doing; and enforcement, the capacity of accounting agencies to impose sanctions on powerholders who have violated their public duties.

(Schedler, 1999, p. 14)

Similarly, Robert Keohane, who develops a concept of accountability for inter- and transnational politics, proposes this definition:

Accountability refers to relationships in which principals have the ability to demand answers from agents to questions about their proposed or past behavior, to discern that behavior, and to impose sanctions on agents in the event that they regard the behavior as unsatisfactory.

(Keohane, 2002b, p. 3)

In the original formulation of principal-agent theory in economics, a number of assumptions generated a clear framework which allowed analysts to focus on how to strengthen accountability. Most cases are based on a contract which clearly defines the principal and the agent. What the agent is accountable for also tends to be uncontested. It is to maximise the principal's expected utility, usually defined in financial terms. Finally, while different types of sanctions and incentives do exist, the main focus in economic relationships is on monetary rewards or sanctions.

All of those parameters, however, have become contested and problematic. Within economics, stakeholder theories, for example, demand recognition of other stakeholder groups as principals, thus also changing what the agent is held accountable for. ${ }^{39}$ When applying the concepts of principal-agent theory to wider social or political situations, the definition of agent and principal changes, as well as the aspects for which the agent is accountable and the sanctions and incentives used to strengthen accountability.

\subsubsection{Who is accountable, to whom, for what and how?}

To characterise any given accountability relationship, it is useful to begin by clarifying the parameters outlined above: Who is the agent? Who are the principal(s)? For what is the agent accountable? and How is this accountability created or strengthened ${ }^{40}$ Without exploring any specific answers, this section sketches the general scope of these questions. 


\subsubsection{Defining the agent}

In the example used above for defining the core of accountability, an accountability relationship was created by one party entrusting money to another. If the agent that is thus created is an individual, it is obvious who can be held accountable for the correct use of the funds. In modern societies, though, many aspects of our political, economic and social lives are dominated by organisations. When it comes to holding organisations accountable, the question of who exactly is accountable can turn into a major problem.

The basic dilemma has been coined the 'problem of many hands' by Dennis Thompson. In an essay analysing responsibility in politics, he defines the problem as follows:

Because many different officials contribute in many ways to decisions and policies of government, it is difficult even in principle to identify who is morally responsible for political outcomes. This is what I call the problem of many hands.

(Thompson, 1980, p. 905)

If a process is too complex to identify individual contributions to specific outcomes, then holding individuals accountable for undesirable outcomes becomes difficult. As a result, individuals as well as organisations as a whole in many instances manage to escape blame and avoid accountability. ${ }^{41}$ This also undermines the preventive function of accountability, encouraging irresponsible behaviour.

Given the far-reaching impact of organisations on modern societies, strategies to address the problem of who can be held accountable are very important. Mark Bovens, for example, distinguishes four different solutions to the problem, each with its own pragmatic and normative advantages and shortcomings.

In systems of corporate accountability, organisations as independent entities are treated like persons. Most legal systems recognise organisations as 'legal persons', that is, as the bearers of rights and responsibilities. This approach makes it easy to identify the agent and can ensure that the organisation is held to account for its misconduct even when the individuals originally responsible for these decisions are no longer present. ${ }^{42}$ Mechanisms relying on corporate accountability can be problematic because organisations often do not behave rationally (hence undermining the preventive function of accountability); because lack of external insight makes control difficult; because organisations can dissolve to escape accountability; and because sanctions can affect people who are not responsible for the misconduct (Bovens, 1998, Chapter 5).

The three remaining solutions are different varieties of holding individuals within organisations to account for corporate conduct. A common form 
is hierarchical accountability. Each official in an organisation is accountable to his superior and the individual at the top of the organisation is held accountable for the behaviour of the organisation as a whole. Again, this model presents a very clear and easy-to-apply solution to the problem of many hands. Problems arise when the leaders of organisations lack adequate information and control over all activities of the organisation. In these cases, hierarchical accountability only has a limited preventive and educational effect on the organisation ${ }^{43}$ (Bovens, 1998, Chapter 6).

Another solution is collective accountability, that is, a system in which each individual member of a group or organisation is held to account for the actions of the collective. This mechanism is certainly very effective in ensuring that individuals are held to account and might have a strong preventive effect. At the same time, most individuals identify as members of specific groups and might feel individually responsible for group conduct. Yet enforcing sanctions to implement collective accountability clearly contradicts fundamental principles of the rule of law and of Western conceptions of morality. The application of collective form of accountability in formalised accountability relations is therefore very rare $^{44}$ (Bovens, 1998, Chapter 7).

Finally, models of individual accountability seek to identify the exact contribution of a person to an outcome and hold her accountable accordingly. This solution corresponds most closely to the normative principles underlying democratic societies but is fully affected by the problem of many hands. To overcome this problem, organisations can, for example, clarify who bears what responsibility and improve the transparency of working processes (Bovens, 1998, Chapter 8).

Since each of these approaches has advantages and shortcomings, Bovens suggests applying a mix of accountability mechanisms depending on the situation. The question of who is held accountable thus remains contested. The problem is exacerbated by the fact that many of the most pressing contemporary public policy problems are influenced by a host of different institutions, groups and individuals. When speaking about the problems that partnerships are designed to address, the problem of many hands therefore applies not only within organisations but also for the multitude of organisations involved.

\subsubsection{Defining the principal(s)}

A politically even more controversial question than who is the agent is the definition of the relevant principal(s). In most cases, multiple actors are recognised or are struggling to be recognised as principals. In businesses, for example, shareholders are broadly accepted as having the right to hold management to account, but in many cases we also see customers, employees and suppliers making accountability claims. Similarly, leading public officials in democracies are accountable to parliament as well as to independent financial 
agencies controlling the use of public funds and to the general public via the media.

The existence of multiple principals raises two problems. Firstly, as we have seen above when defining agency costs, monitoring the agent is costly for the principal. If multiple or fragmented principals exist, ${ }^{45}$ a collective action problem arises since no single actor has an incentive to bear the costs of providing information that could be used by all principals to monitor the activities of the agent. ${ }^{46}$

The second, more intractable problem lies in the fact that different principals have different, potentially conflicting criteria for judging the agent's conduct. Thus shareholders hold managers accountable for high returns on investment, employees for high salaries, good working conditions and job security, while customers emphasise low prices and high product quality. ${ }^{47}$ Similarly, public officials are held to account for producing outcomes by the media and public, while financial oversight committees demand accountability for the correct use of funds. ${ }^{48}$

Agents can use the existence of multiple principals to avoid accountability. ${ }^{49}$ But they can also accept the complex task of assigning priorities among principals and balancing their various claims. R. Edward Freeman in his argument to adopt a stakeholder theory of the firm - which is no other than to recognise other stakeholders as co-principals on an equal footing as shareholders - described the scope of the challenge confronting managers:

The task of management in today's corporation is akin to that of King Solomon [...] management must keep the relationships among stakeholders in balance.

(Freeman, 2001, p. 44)

All partnerships face a range of different principals. Depending on the formality of their accountability claims, we can generally distinguish three levels of accountability holders: legal and fiscal authorities, formal principals and informal principals. The different layers are illustrated in Figure 2.3.

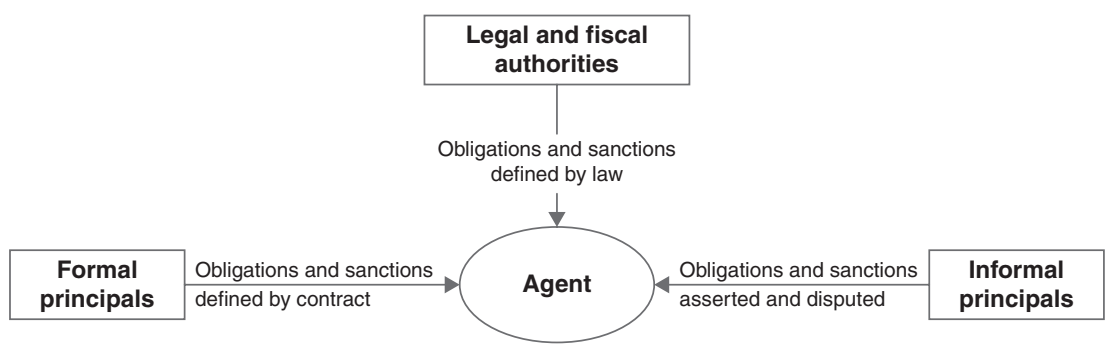

Figure 2.3 Layers of principals 
Legal and fiscal authorities: The level of accountability with the strictest and most formalised definition of both obligations for agents and sanctions in case of their violation is to legal and fiscal authorities.

In the debate about institutions that act at the transnational or international level, legal and fiscal accountability is often neglected, because there is no all-encompassing international legal code or court system. Yet almost all institutions are located and operate on national territories and are thereby bound by their respective rules and regulations. ${ }^{50}$ Multinational corporations, for example, despite their power have to abide by the rules of the countries they operate in. Integrated international markets and financial systems do, however, allow them to choose which national regulatory and enforcement system they want to be subject to. This can put corporations in a strong position when they lobby for changes in national rule systems.

Formal principals: The next level of accountability is that defined by contracts or other means of formal delegation. In these cases, contracts, statutes or briefs establish who transfers what authority to whom. Thus they clearly define the identity of both principal and agent, as well as the obligations of the agent and sanctions that apply in case of non-compliance. As a result, formal accountability relationships tend to be uncontested in principle. Disputes may arise over the details of honouring obligations or the application of sanctions but not the existence of an accountability relationship itself. Examples for such principal-agent situations include the relationship between company owners and managers, between elected governments and their ministers as well as their delegations in international organisations and between civil society organisations and their members or donors.

Informal principals: A third level of accountability is based on the informal, implicit or hypothetical delegation of authority. As argued in greater detail in section 3.2.3, organisations often assume authority without explicit prior authorisation. In these cases, those who originally or rightfully hold the authority now exercised by the organisation have a claim to accountability. The lack of formality means, however, that these claims are often contested.

In practice, the relative power of groups or individuals often determines whether they can hold an agent accountable. Establishing clear criteria for determining who should be recognised as a principal is nevertheless important, not least because legitimacy itself has become a currency of power in a globalised world.

\subsubsection{What are agents accountable for?}

Accountability was defined above in the context of a principal-agent relationship. This makes it easy to define what an agent is accountable for in abstract terms. Agents are accountable for using the authority given to them in a way that fulfils the principal's expectations. When somebody entrusts 
the management of resources to somebody else, for example, she probably expects the agent to use those resources efficiently and effectively to achieve the agreed goal.

But principal-agent relationships can take on very different forms. In addition, any single agent can be subject to the accountability demands of a variety of principals. It is therefore impossible to describe all the possible aspects an agent can be held to account for in concrete terms. Generally speaking, though, agents are held accountable for the way they handle resources, for their compliance with rules and procedures and for the outcomes they produce.

Accountability for finances: Financial accountability could be subsumed under the other two headings relating to processes and outcomes, but it deserves to be treated separately because it is so central both to our understanding of accountability ${ }^{51}$ and to the workings of organisations.

Agents can be held accountable for three different aspects of the way they handle resources. Firstly, it can concern the sources of an agent's financial and other means. Whoever provides an organisation with resources gains influence over it. This can make the agent dependent and corrupt its impartiality. Public agencies, many civil society organisations and institutions involved in evaluation and monitoring are thus often held accountable for the sources of their funds. ${ }^{52}$

Secondly, agents are accountable for using their resources efficiently and effectively. Those who provide an organisation with resources usually want to ensure the agent uses them in the best way for reaching the desired goals. In the private sector, return on investment is a common measure for establishing whether resources were well used. In the public and civil society sectors, similar measures are usually more difficult to find.

Thirdly, the way an agent handles resources can be under scrutiny. Because efficiency and effectiveness are often hard to measure in public agencies and civil society organisations, more weight tends to be attached to the rules and processes for managing resources. Thus donors and public agencies often predetermine in great detail which resources can be allocated for what purpose and agents are held accountable for following those rules. The key to proper financial management - professional bookkeeping and accounting, combined with adequate reporting - though, is expected of organisations in all three sectors.

Accountability for finances can create considerable conflicts and dilemmas. Firstly, different principals often have different views on what resources should be spent on. Company managers, for example, can be pressured by shareholders to deliver maximum dividends. Employees may favour higher wages; consumers usually opt for lower prices and NGOs lobby for a greater share of resources to be invested, for example, in environmental protection.

Secondly, the three aspects of financial accountability are not necessarily compatible. An environmental NGO that rejects contributions from oil 
companies to maintain its independence, for example, may be unable to reach its goals because of a lack of resources. Similarly, professional and accurate accounting and reporting is costly and can divert resources away from other purposes. And strict and detailed rules on how to handle resources can curtail the flexibility of agents to such an extent that their efficiency suffers. As further discussed in section 2.3, organisations must therefore carefully determine which aspects of accountability they want to stress.

Accountability for compliance with rules and processes: Another general aspect that agents are held accountable for is their compliance with rules and procedures. Rules and predefined procedures serve to control the behaviour of agents. They can do so by directly protecting the interests of others. Companies, for example, in many countries have to pay their employees minimum wages and are restricted in their rights to fire them. Other rules and processes are components of accountability mechanisms. They make it easier for principals to enforce their accountability claims. An example of this is the right of workers to unionise or to participate in the management of the company. Principals are often interested in enforcing compliance with these rules and processes because it allows them to create effective accountability for their other interests.

The rules and processes regulating the behaviour of agents can be defined by governmental authorities in laws, regulations and fiscal rules. But they can also be determined by principals. When a new agency is created, for example, the founding institutions create a statute and by-laws determining the agency's mandate and governance. Common types of rules and processes that agents are expected to follow include:

- Legal and fiscal rules: The rules and processes prescribed for organisations are complex and vary between countries as well as between different organisational forms. They pertain, for example, to the requirements for registration or incorporation, the treatment of employees or competitive practices. Compliance with these rules can be enforced by national judicial systems. Where judicial systems work well, accountability for compliance with legal and fiscal rules is therefore high.

- Decision-making procedures: Another important set of rules and prescribed procedures covers the way organisations make decisions. This includes regulations on which body can take which decisions by what decision rule, as well as who needs to be included or consulted and who is bound by the decision. Decision rules can be important mechanisms to strengthen accountability. They help determine who bears what responsibility for a certain outcome and allow those principals who are included in the process to articulate their preferences directly. Irrespective of the outcome of a decision, principals therefore often hold agents accountable for following the correct procedures when taking decisions. 
Which decision-making procedures are set for an organisation is highly dependent on context. The requirements are often stricter for the public than the private sector and more demanding for taking strategic decisions than for implementing them. A standard that all types of organisations can be held accountable for is due diligence. ${ }^{53}$ Principals demand due diligence from managers and bankers in investment decisions. But the public also holds public agencies and NGOs accountable for 'not doing their homework properly'. Thus Greenpeace, after the Brent Spar campaign, as well as the Bush administration in the follow-up to the invasion of Iraq experienced a sharp drop in public support. ${ }^{54}$

- Transparency: A final crucial set of rules and regulations determines what information an organisation has to provide to whom. As we have seen in the definition of accountability above, access to reliable and useful information is essential to any accountability mechanism. Transparency requirements therefore figure prominently in the rules and procedures laid down for organisations ${ }^{55}$ and principals are often keen to enforce compliance with these rules. The rules regulate not only what needs to be communicated but also determine requirements for the quality of information. Many organisations, for example, are obliged to conform to strict standards in their accounting and reporting, and must have their accounts and activities verified by independent auditors. ${ }^{56}$

Accountability for results: Perhaps the most obvious aspect that organisations are held to account for are the outcomes or results of their work. This includes firstly which goals an organisation pursues. Take, for example, an advocacy NGO that claims to represent the interests of indigenous people and seeks to stop the construction of a dam on their behalf. The group of indigenous people may actually disagree and try to hold the NGO accountable for its goals. Similarly, citizens hold governments accountable for the goals they pursue by endorsing or rejecting proposed policies in elections.

Secondly, accountability for results can refer to the way in which an organisation achieves its aims. The main question here is whether the organisation is efficient in its operations. Consumers, for example, can hold companies accountable for efficiency by choosing products that, at similar quality, are offered at a cheaper price. Comparison is more difficult in the public and civil society sectors. But donors, for example, increasingly use measures like the ratio of overhead costs to total budget as shorthand for efficiency.

Finally, principals can focus on the quality of results. Is the organisation effective and successful in reaching the goals it set for itself? A government that was voted in on the promise to reduce unemployment, for example, may lose subsequent elections if it fails to deliver effective results. Similarly, a research institution can quickly lose its reputation as well as funding if its results fail to live up to scientific standards, just as a professional auditor will find himself in court and out of business if his results are not accurate and impartial. 
In practice, creating accountability for the efficiency and quality of results is often difficult. The chief reason for this is that some outcomes are much easier to evaluate than others. Thus, it is much easier to judge the financial returns of an investment than to measure the social or environmental effects of an investment decision, policy or civil society campaign. As a result, accountability for easy-to-measure results often takes precedence over accountability for more fuzzy kinds of results, or accountability for easily evaluated procedural aspects dominate outcome accountability. As Robert Behn argued persuasively for accountability in the political sector, this can lead to serious shortcomings in the overall workings of a political system (Behn, 2001).

\subsubsection{How is accountability created or strengthened?}

The definition of accountability proposed above contained a description of the basic mechanism through which accountability works. An agent behaves in a certain way. Information about these activities is used by the principal to evaluate the agent's behaviour. Depending on whether or not the behaviour conforms to the principal's expectations, she will apply sanctions to control the agent's activities, thus establishing what could be termed 'retroactive accountability'. If the agent can anticipate this reaction, the expectation of sanctions influences his actions, hence generating 'proactive' or 'preventive accountability'. ${ }^{57}$

Accountability can go wrong at each of these four steps: Firstly, the effects of the agent's behaviour can be unclear. ${ }^{58}$ Secondly, the information available to the principal can be biased or insufficient for an appropriate evaluation. Thirdly, accountability can fail if the expectations of the principal or principals are unclear or contradictory. Finally, the principal might not possess sufficient means for sanctioning the agent or his threat to use those sanctions may not be credible enough to preventively change the agent's behaviour.

Mechanisms to create or strengthen accountability, then, are measures that address any of these issues. ${ }^{59}$ Since an accountability system is only as strong as its weakest point, ${ }^{60}$ effective accountability strategies address all four areas at the same time, or focus on the area with the greatest shortcomings.

Clarifying the agent's contributions and responsibilities: There are two situations in which the effects of an agent's behaviour are unclear: Firstly, the activities and responsibilities of an actor may be well known, but the consequences of these actions are not. Many environmental problems, for example, are causally extremely complex and scientifically disputed. Apart from improving the scientific evidence relating to the problem, accountability can be improved if very specific behavioural goals are defined based on existing evidence. This happened, for example, in the area of climate change, where the Kyoto Protocol defined specific targets for the reduction of $\mathrm{CO}_{2}$ emissions. These are now used to either make companies reduce their emissions or pay for additional emission rights. 
Secondly, this lack of clarity can occur when the agent's responsibilities are unclear. The obvious remedy here is to assign responsibilities and tasks more clearly. While the agents must retain flexibility to react to unexpected developments, a clearly defined mandate is important to establish accountability within an organisation, and also when different groups or institutions cooperate to reach a joint goal.

Improving the provision of information: As we have seen above, information asymmetry is one of the major drivers of agency costs. Correspondingly, transparency, or the availability of correct and useful information, is a central precondition for accountability. ${ }^{61}$ The issues relating to transparency include the scope, source, quality, credibility, formats and associated costs of information:

Generally, principals want information on anything they hold the agent accountable for. This can refer to an organisation's finances, its operating procedures and internal governance, as well as the outcomes produced in different areas. The challenge for any organisation is to find the right balance between the necessary scope and degree of detail in reports and their usability. In addition, certain aspects of an organisation's work might be subject to legitimate confidentiality requirements, such as, for example, the takeover plans of a company.

Information can be generated by both the agent and the principal. In both cases, the quality of information is crucial and different types of reporting and auditing standards are used to guarantee quality. When it is the agent who makes information available, he often encounters credibility problems. These are most commonly addressed through external verification. ${ }^{62}$ When the principal generates the necessary information, credibility can also be an issue (e.g. Greenpeace's Brent Spar episode), but in addition, the question of how sources of information are protected and how the agent deals with information requests are salient. ${ }^{63}$

Another important aspect concerns the format in which information is transmitted. To be useful, the format must fit the needs of the respective audience. Thus while publications of English language annual reports on the Internet might be appropriate for satisfying the information needs of Western NGOs, they might not be accessible to local communities in the developing world. Here, signs, billboards or public discussions in the local language might be necessary to convey information effectively.

Finally, the costs of providing and using information have to be considered. Providing detailed reports and evaluations of an organisation's activities can be highly complex and requires specialised skills and staff time. From the perspective of an agent, bearing this cost is only worthwhile if it serves to avert sanctions. For principals, particularly when they are fragmented, generating information can lead to a collective action problem. Stock markets have solved this problem by specifying disclosure requirements for listed 
companies and by employing rating agencies to provide additional information and evaluate available data.

Clarifying the principal's expectations: To create a strong accountability relationship it is also crucial that the principal's expectations be clearly defined and articulated. Clearly defined and, where possible, operationalised expectations form the basis for evaluating the agent's behaviour.

In many cases, the expectations and demands of a principal are ill defined. This can be the case in situations involving formal delegation. Even where a contract defines the principal-agent relationship, the tasks and achievements expected of the agent can be too broad to provide any practical guidance. ${ }^{64}$ But a lack in clarity is even more frequent in informal accountability relationships such as between consumers and producers or civil society groups and political institutions. Here, expectations are often not articulated at all or are unclear and subject to change.

When the principal is a fragmented and dispersed group of individuals or organisations, formulating precise expectations presents a formidable challenge that might require the installation of a centralised spokesperson. The task is easier when the principal is an individual or a coherent group or institution. Here, the scope for improvement is often large, particularly in the political sphere. Yet a fundamental tension will always remain between the desire to define precise steps and responsibilities in a mandate and leaving the agent with a sufficient degree of freedom to react to unforeseen developments. ${ }^{65}$

The case becomes even more complex when different principals with diverging interests and expectations exist. As Robert Keohane pointed out, this can be abused by agents to avoid accountability. ${ }^{66}$ The flipside of this coin is that those agents who do not want to escape accountability and are confronted with multiple, conflicting expectations can find it impossible to do justice to all principals. ${ }^{67}$ Despite their best intentions, they can be subject to sanctions from various sides. To avoid sanctions, the agent can create transparency about which expectations exist and how she balances or prioritises them, hoping for understanding and approval from the principals. Alternatively, she can attempt to make the principals (or at least some of them) to agree on a coherent set of objectives among themselves. Companies conducting multi-stakeholder dialogues, for example, can use this forum for either of the two strategies of explaining and creating transparency or developing a consensus among stakeholders.

Strengthening sanctions and incentives: The ability to impose negative or positive sanctions is the ultimate means through which principals control the agent's behaviour. The types of sanctions available to different groups or 
individuals vary considerably in their nature and their salience to the agent. They include: ${ }^{68}$

- Legal and fiscal sanctions: Organisations, even if they work on a transnational or international level, are bound by the laws and regulations of the country they operate in. Legal and fiscal systems around the world define very explicit rules for the behaviour of individuals and corporate actors, as well as the sanctions to be applied in case of their breach. Both the content of these rules and sanctions and the degree of their enforcement vary significantly between countries. Well-functioning legal and fiscal systems can impose tough sanctions and can therefore be very effective in creating accountability. This accountability, though, is usually limited in scope, sanctioning only outright transgressions of norms.

- Elections: In democratic political systems, elections are commonly used as sanctions to ensure the political leadership respects the preferences of the people. ${ }^{69}$ Elections are also used within many organisations or cooperative bodies to make elected officials accountable to their electorate.

- Disciplinary measures: In hierarchical organisations, superiors can usually resort to disciplinary measures for holding their staff to account for their actions. These can be quasi-legal (as is the case in military organisations) or result in pay-cuts, changes in the job description or dismissal.

- Financial incentives: While legal sanctions, elections and disciplinary measures have a strong impact on agents, financial incentives and sanctions can be more easily fine-tuned and thus allow for a more differentiated form of accountability. Financial sanctions are used to hold both individuals and organisations to account. Thus managers' salaries are often linked to the company's performance, consumers and investors can exert pressure through their market decisions and donors often link their contributions to specific demands.

- Withdrawal and voluntary compliance: A potent sanctioning mechanism for those who might not have formal or financial means to influence an organisation or process is the option to stop participating in it ${ }^{70}$ or fail to comply with its resolutions. To be effective, the actor who denies participation or compliance must be critical to the issue at hand. Thus, for example, the refusal of the US to participate in international agreements like the Kyoto Protocol seriously affects its effectiveness. Similarly, the quantity of individuals leaving the GDR prior to the fall of the Berlin Wall seriously undermined the state's legitimacy. In the corporate sector, the operations of a company can be threatened if many employees quit their jobs or lay down their work in strikes. At the international level, where no centralised enforcement mechanism exists, the necessity to achieve voluntary compliance with norms and resolutions is one of the key levers for groups demanding the consideration of their interests, hence creating accountability for inclusion. 
- Reputation: A more subtle and diffuse type of sanction relates to an individual's or an organisation's reputation. The opinions held by relevant groups about an organisation or individual matter since they influence their ability to operate. Reputation affects, among others, who want to work for, engage with or vote for the actor and how seriously products or ideas are taken. ${ }^{71}$

- Protest and violence: Finally, all those who feel they do not possess sufficient alternative sanctions to hold an agent accountable can resort to protests or even violence to make their claims heard. From the so-called Monday demonstrations against labour market reforms in Germany, via the street protests against the World Trade Organization's (WTO) policies in Seattle to acts of sabotage and violence against oil firms operating in the Nigerian Delta region, it is particularly those who feel excluded and marginalised who resort to protests and violence to create accountability.

With such a broad array of potential sanctions available, two main strategies exist to strengthen accountability based on sanctions. Firstly, institutional structures can be changed to give specific principals access to new kinds of sanctions. This can mean the creation of entities organising collective action to increase the sanctioning potential, such as trade unions or NGOs giving voice to marginalised groups. Or it can mean the inclusion of groups in decision-making processes, as is the case when corporations conduct multi-stakeholder dialogues or when the UN grants NGOs official status in its negotiations. ${ }^{72}$ The latter process is often an attempt to change available sanctioning mechanisms from those that work crudely and ex-post facto like protests and violence to more differentiated ones that are better suited to creating proactive or preventive accountability such as elections or participation in decision-making processes.

Secondly, the accountability effect of existing sanctions can be strengthened by improving their enforcement. Better enforcement not only allows stronger retroactive accountability but thereby also makes the threat of sanctions more credible, thus enhancing preventive accountability. One way to make the enforcement of sanctions more reliable is the creation or strengthening of enforcement institutions, such as state prosecution offices, disciplinary committees in institutions or control and evaluation units in donor organisations. Another way is to make sanctions more immediate and link them more directly to the agent's behaviour. Thus, for example, managers' salaries are now often directly tied to company performance. This means that sanctions and rewards are triggered automatically.

\subsubsection{When is the agent interested in strengthening accountability?}

We have now seen how accountability can be created or strengthened at each of the four steps involved in the basic accountability mechanism. Measures to improve accountability can be taken by both sides, the principal(s) and the agent. While it seems obvious why principals want to create strong 
accountability (namely to align the agent's behaviour as much as possible with their own interests and goals), it might not be so clear why an agent might be interested in strengthening his own accountability.

Indeed, Keohane suggests that 'Opportunistic agents will seek to design institutional arrangements that only nominally control their behavior' (Keohane, 2002b, p. 14). Similarly, Robert Behn argues that agents have a very clear view on accountability which does not make it sound like a desirable outcome: 'Those whom we want to hold accountable have a clear understanding of what accountability means: accountability means punishment' (Behn, 2001, p. 3).

Yet there are clear instances in which agents do take measures to make themselves more accountable. Of course, these actions can be taken in response to or anticipation of pressure for reform. But it can also be in the agent's interest to actively push for improved accountability. Jensen describes this in his early definition of agency costs:

In addition in situations it will pay the agent to expend resources (bonding costs) to guarantee that he will not take certain actions which would harm the principal or to ensure that the principal will be compensated if he does take such actions.

(Jensen and Meckling, 1976, p. 5, emphasis original)

Figure 2.4 illustrates the motivation of principal and agent in creating or strengthening accountability. ${ }^{73}$ The situation is presented as a simple game involving two steps. Agent A can either pursue his own or the principal's interest. Principal P can either apply sanctions to A or not. The payoff structure (payoff $\mathrm{A}$, payoff $\mathrm{P}$ ) shows that the optimal outcome from the perspective of the agent is 'pursue A's interests' and 'no sanction'. The principal,

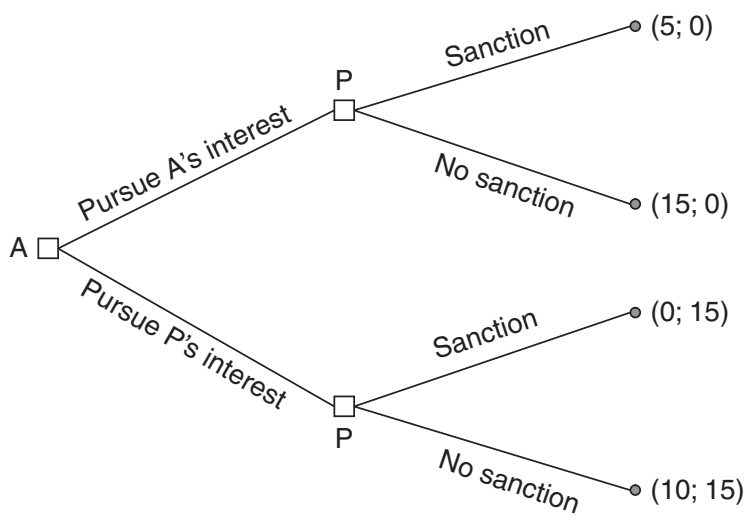

Figure 2.4 The principal's and agent's interest in accountability 
by contrast, has a strong preference for the agent to pursue P's interests. Therefore, the principal has an interest in making the threat of sanctions credible enough to induce A to choose 'pursue P's interests'.

From the perspective of the agent, the situation is slightly more complex. His first instinct is probably to try to weaken accountability so that he can pursue his own interests without incurring any sanctions. Two considerations, however, can change this calculus. Firstly, the principal is probably only willing to engage in this game at all or to play it again if she sees a reasonable chance that the agent will pursue P's interests. As long as the agent derives a greater benefit from playing than from not playing, he has an interest in making a credible commitment not to abuse his authority, that is, in strengthening accountability. ${ }^{74}$ Secondly, the agent also has a strong motivation to avoid a situation where he does his best to act in the principal's interests, but gets sanctioned nevertheless. He can reduce this risk by demanding that the principal clearly articulates her expectations and preferences and by ensuring that the principal receives adequate information about the agent's behaviour. In this sense, too, the agent can be interested in strengthening the accountability relationship.

\subsubsection{The accountability dilemma}

The term 'accountability' carries overwhelmingly positive connotations. Many therefore assume that it is simply a case of 'the more, the better' ${ }^{75}$ This is particularly the case in the international sphere, where researchers and activists now increasingly come to see mechanisms to strengthen the accountability of different organisations as a means to balance the democratic deficit of global institutions. ${ }^{76}$

While accountability does play an important role in making the operations and policies of influential actors more responsive to the needs and interests of those affected, it is not always a case of 'the more, the better'. In Mark Boven's words, 'Public accountability may be a good thing, but we can certainly have too much of it' (Bovens, 2005, p. 194).

Accountability relationships can have negative impacts in three main respects. Firstly, principals can hold agents accountable according to multiple, sometimes even contradictory standards. Where this is the case, accountability demands can have a paralysing effect on organisations. In addition, even well-intentioned agents will find it impossible to fulfil all expectations at once and face undeserved sanctions. Jonathan Koppell has described organisations trying to satisfy various conflicting accountability demands as suffering from a 'multiple accountabilities disorder' (MAD). In his experience, such situations are likely to undermine the overall accountability of an organisation: 'Rather than satisfying all conceptions of accountability, the MAD-afflicted organization often satisfies none' (Koppell, 2005, p. 99).

Secondly, accountability mechanisms generate costs. Creating transparency and monitoring activities, for example, requires substantial efforts on 
the part of the principal as well as the agent. Where sanctions are imposed, they further reduce the benefits of at least one of the sides involved.

Thirdly, excessive accountability can hamper flexibility and innovation. When accountability means strict control, this constricts the agent's flexibility and ability to react to events and new developments. This means that the agent may not be able to act and to use resources as efficiently as he otherwise could. In addition, the threat of strong sanctions may lead many agents to act more cautiously and avoid taking risks. Risk taking, however, is essential for developing innovative solutions to problems.

Accountability can thus involve both benefits and negative consequences. ${ }^{77}$ In the literature, opinions about the overall effect of accountability on performance diverge. First, there is a range of authors who see a positive effect. Thus, for example, Melvin Dubnick quotes numerous sources and describes the 'promise of performance' as follows:

According to proponents of accountability-centered reforms, enhanced accountability will (among other things) result in [...] improvements in the quality of government services.

(Dubnick, 2003, p. 1)

This view is contradicted by those who see a conflict between accountability and performance. Peter Self described this dilemma as a central one:

[T]he tensions between the requirements of responsibility or 'accountability' and those of effective executive action can reasonably be described as the classic dilemma of public administration.

(Quoted in Behn, 2001, p. 11)

Alnoor Ebrahim makes a similar claim for non-profit organisations (NPOs). He contends that

for NPOs and nongovernmental organizations (NGOs) involved in activities of complex social development and poverty alleviation, too much accountability can hinder them in achieving their missions.

(Ebrahim, 2005, p. 56)

This last quote already indicates that authors searching for an answer to the question of whether accountability enhances or hinders performance that is valid across the board may be misguided. Many researchers reject the assumption that accountability has either necessarily positive or always negative consequences. Aucoin and Heintzman, for example, argue that

[p]itting accountability against performance does not, in our view, address the issue in the most constructive manner. [...] Improving accountability 
arrangements does not necessarily improve performance, but the proposition that there can be improved performance in the absence of improved accountability is a proposition that cannot be sustained.

(Aucoin and Heintzman, 2000, p. 54)

Similarly, Melvin Dubnick comes to the conclusion that

we cannot and should not continue to rely on the assumed relationship between accountability and performance [namely, that accountability improves performance].

(Dubnick, 2003, p. 40)

Rather than trying to solve the question of whether or not accountability enhances performance once and for all, researchers should therefore concentrate on determining under which circumstances which types of accountability have an overall positive effect on the situation. Robert Behn's book Rethinking Democratic Accountability is a good example for such an approach. He develops detailed proposals for shifting accountability in public administration from accountability for finances and fairness to more accountability for performance (Behn, 2001). This book hopes to make a contribution in a similar vein. It develops an abstract framework for defining what type of accountability is appropriate for which kind of organisation and develops concrete standards indicating which groups of partnerships should adopt which accountability measures.

\subsection{Partnership accountability}

Partnerships as cooperative governance mechanisms and the concepts and practices of accountability each on their own raise sufficient research puzzles to fill volumes. What is it, then, that makes accountability important for partnerships and why do partnerships create particularly challenging questions for accountability?

This section focuses on the special nature of partnership accountability in terms of the salience of accountability to partnerships, the specific acuteness of accountability trade-offs and the distinctive complexity of developing accountability concepts and mechanisms for partnerships.

\subsubsection{Political salience}

Accountability is important for any organisation that influences the lives of individuals. Yet in the debate about partnerships involving actors from the public, corporate and civil society sectors, the issue is particularly salient. As argued in the introduction to this book, most principled objections against partnerships are based on concerns about accountability.

Fears run deep that we cannot hold to account remote powers whose actions have far-reaching impacts on our lives. This is especially the case in 
societies accustomed to liberal-democratic political arrangements, which at least theoretically grant their citizens extensive controls over government operations. Take for instance the intense debate about the 'democratic deficit' of the European Union. It shows how sensitively people react when their governments surrender authority to less directly accountable institutions. ${ }^{78}$ By agreeing to common decision-making procedures, partners also delegate some authority to partnerships. This stretches the accountability links to the partners' original accountability holders and thus weakens their control over outcomes. If the partnership does not have appropriate accountability mechanisms in place to compensate for this accountability loss, a political backlash against its activities can be expected.

At the same time, partnerships are often created to address accountability problems of the partner organisations. The focus here is less the absolute level of accountability than to whom organisations are accountable. Reformers often demand greater inclusiveness and accountability to various stakeholder groups from government, international organisations and corporations. Partnerships are one avenue for achieving just this. By giving important stakeholder groups a say in decisions, partnerships can create more accountability. ${ }^{79}$ Partnerships thus present challenges to established forms of accountability, yet promise more accountability to new principals.

Beyond that, reflections about partnership accountability have a special relevance now because most partnerships are still relatively young, in particular those launched during or in the aftermath of the 2002 World Summit on Sustainable Development. It is now that standards for their internal governance structures, reporting requirements, transparency and other accountability mechanisms are being defined - yet most actors are still lacking the necessary experience with partnerships to take informed decisions on these issues.

If we take other institutional developments as an indicator, we can observe that accountability systems are typically reformed or strengthened after they failed, that is, in response to disasters and scandals. Thus the scandals that led to the resignation of the European Commission (EC) under Jacques Santer triggered important reforms concerning the transparency of EC procedures and the powers of control of the European Parliament. ${ }^{80}$ Similarly, the mismanagement and accounting problems leading to the spectacular collapse of numerous companies like Enron encouraged corporate governance reforms in the US. ${ }^{81}$ While these changes will hopefully help prevent similar problems in the future, the damage in terms of losses of financial resources and trust was done.

Research leading to a better understanding of the types, mechanisms, trade-offs and minimum requirements of partnership accountability could contribute to the preventive installation of adequate accountability mechanisms. This would give partnerships the chance to develop good governance structures without experiencing disastrous failures. 


\subsubsection{Importance of trade-offs}

As discussed above, accountability can be strengthened by addressing the clarity of the agent's responsibilities, the flow of information, the clarity of the principal's expectations and criteria for evaluation or the availability of sanctions. Each element in the accountability chain, though, has its downside:

- Very clearly demarcated responsibilities of individual actors make it more difficult to adapt to changed circumstances and might prevent these actors from focusing on the big picture;

- providing information that is timely, accurate and fits the needs of different principals is labour-intense and creates substantial costs, thus diverting resources away from other uses;

- operationalising principals' expectations is fraught with difficulties and can deflect attention away from broader goals and defining common expectations of different principals can be a lengthy, if not impossible, process;

- strong sanctions diminish the readiness to assume risks, while giving many stakeholders access to new sanctions by including them can make decision-making processes very cumbersome.

The arguments mentioned so far apply to all actors that are accountable to someone. But just as the issue of accountability is especially relevant for partnerships, so are the trade-offs. Firstly, partnerships in many cases are not strongly institutionalised. Designed at least in part as an alternative to overly bureaucratised and inefficient traditional institutions, partnerships are a particularly valuable tool of governance when they remain flexible. This means that the risk of losing the ability to adapt quickly to new developments is especially high for partnerships.

Secondly, the provision of timely, relevant and accurate information presents bigger problems to new than to established institutions. When institutions are in the early stages of their development, they typically have few staff members and very constrained resources. That makes it difficult to spare the necessary time and money for providing information. In addition, young institutions change at a faster pace than old ones, making it more difficult to keep information up to date. Since the fashion of cross-sector partnerships is a relatively recent phenomenon, most partnerships are still young, making the costs of providing information relatively high. ${ }^{82}$

The third point relates to the difficulties that arise when different principals pursue diverging goals. The interests of different accountability holders rarely converge. Yet for most other types of institutions it is possible to prioritise these interests depending on the strength of the sanctions the principals have at their disposal. ${ }^{83}$ Partnerships by definition include actors from the public sector, businesses and/or civil society as partners. This means that groups with potentially widely diverging interests belong to the innermost 
layer of accountability holders and enjoy roughly equal status. Problems of conflicting goals can therefore not be solved by prioritising one principal's issues over the others. Partnerships either have to resolve the conflict by reconciling interests and finding compromises - often a long and burdensome process - or ignore it at the risk of making meaningful partnership activities impossible.

Finally, sanctions work most effectively if they work preventively. For an agent to be able to adapt his behaviour preventively, he must be in a position to anticipate under what conditions which sanctions will be applied. This is unproblematic where a partnership explicitly defines these sanctions (e.g. by linking the salaries of partnership managers to performance or by deciding that the executive board has to be regularly approved through elections). For many other issues, however, expectations are shaped by different corporate or national cultures. Thus both the rules and the likelihood of their enforcement can vary significantly between national legal systems as well as between partner organisations. This can result in a lack of clarity about sanctions and thereby undermine their effectiveness as means of prevention.

\subsubsection{Complexity}

Finally, as argued in the Introduction, defining concepts and effective mechanisms of accountability is even more complex for partnerships than for more traditional institutions. This complexity - together with the salience of the topic and the enhanced relevance of trade-offs - makes it important to arrive at a clear empirical, analytical and normative understanding of partnership accountability.

More specifically, the complexity stems from two major factors. Firstly, partnerships engage in a broad variety of activities, ranging from advocacy and awareness raising, generating information and verifying compliance, setting norms and standards to funding or coordinating policy implementation. As will be argued in Chapter 3, partnerships ought to embrace different accountability arrangements depending on what functions they exercise. Between the various partnership types, there are significant, albeit inconsistent, variations in accountability.

Secondly, understanding and evaluating partnership accountability is complex because accountability concepts and mechanisms have so far been developed mostly for traditional institutions. The accountability traditions of democratic governments, international organisations, corporations and civil society organisations differ significantly. ${ }^{84}$ Since partnerships include actors from and perform the functions of several of these organisations, we need to define standards for partnerships that take these differences into account. This will be the subject of the normative inquiry in the following chapters. 